\title{
Molecules controlling lymphocyte-endothelial interactions in lymph nodes are produced in vessels of inflamed synovium
}

\section{A J FREEMONT}

\section{From the Department of Pathology, University of Manchester}

SUMMARY In vitro lymphocyte adhesion to, and selective radiosulphate uptake by, endothelial cells has been demonstrated in diseased synovium of patients with rheumatoid disease, osteoarthritis, and the peripheral arthropathy associated with ankylosing spondylitis and ulcerative colitis. These characteristics have been described previously in endothelial cells functionally specialised for promoting lymphocyte traffic from blood to lymph node parenchyma. It is suggested that these observations indicate that some synovial vessels may be responsible, at least in part, for the selective accumulation of lymphocytes in the tissue. Manipulation of the development of this type of vessel may offer a novel way of influencing the progress of inflammatory arthropathies.

Key words: lymphocyte migration, synovium, high endothelial venules.

It is believed that lymphocytes derived from the recirculating pool may modulate tissue damage in chronic inflammatory arthropathies, ${ }^{12}$ but the mechanisms by which these cells enter synovium are poorly understood. It has been proposed that changes observed in local venules in sites of lymphocyte accumulation in diseased synovium may indicate endothelial specialisation for promoting selective lymphocyte traffic between blood and tissue parenchyma. ${ }^{3}$ In support of this proposal it has been noted that these vessels have the morphological and histochemical properties of human lymph node high endothelial venules (HEV) ${ }^{4}$ which are the exclusive site of lymphocyte traffic from blood to nodal parenchyma. HEV are known to influence lymphocyte traffic via a series of complex endothelial-lymphocyte interactions mediated, in part, by macromolecules produced by their endothelial cells (HEC). ${ }^{5-8}$

Two of these interactions, calcium dependent binding of lymphocytes to HEC ${ }^{56}$ and secretion by HEC of a sulphated glycolipid ${ }^{7}$ which will induce lymphocyte migration into skin if injected intradermally, can be assayed in vitro; the first, by measurement of the adhesion of lymphocytes to the cut surface of HEV in lymph node slices ${ }^{56}$; and the

Accepted for publication 22 May 1987.

Correspondence to Dr A J Freemont, Department of Pathology, University of Manchester, Stopford Building, Oxford Road, Manchester M13 9PT. second, by studying, microautoradiographically, the kinetics of $\mathrm{HEC}{ }^{35} \mathrm{~S}$ incorporation. ${ }^{79}$

The obvious similarities between lymph node HEV and the HEV-like vessels in diseased synovium have lead to speculation that they may be functionally similar, ${ }^{3}$ and in particular that the mechanisms governing endothelial-lymphocyte interactions may be the same.

In the study reported here this possibility has been examined by comparing in vitro lymphocyte adhesion and sulphate uptake in human lymph node HEV and synovial HEV-like vessels.

\section{Materials and methods}

The study material consisted of 10 human lymph nodes and 20 synovial biopsy specimens. The lymph nodes comprised four axillary nodes obtained at mastectomy for carcinoma of the breast, four cervical lymph nodes biopsied during investigation of unexplained lymphadenopathy, and two paraaortic nodes removed at staging laparotomy for Hodgkin's disease. Serial sectioning showed only 'reactive' changes within the nodes.

Synovia from knees and hips were obtained at synovectomy or joint replacement; seven from $\stackrel{\leftrightarrow}{\Phi}$ patients with definite or classical rheumatoid disease, two with the synovitis of ankylosing spondylitis, one with the arthropathy associated with ulcerative colitis, and 10 with osteoarthritis. 
Tissue obtained at surgery was processed in three ways:

One part was fixed in formalin, embedded in paraffin wax, sectioned at $5 \mu \mathrm{m}$, and stained with haematoxylin and eosin.

A second was snap frozen in isopentane cooled in liquid nitrogen and sectioned at $10 \mu \mathrm{m}$ in a cryostat. One section from a lymph node and one from synovium were placed either end of a gelatin coated microscope slide and a ring $2 \mathrm{~cm}$ in diameter drawn around each with a wax pen. The slides were then immersed in $2 \%$ glutaraldehyde in phosphate buffered serum (PBS) (pH 6.3) for 10 minutes. After fixation the slides were washed in PBS and treated with $0.25 \mathrm{M}$ lysine to block residual unreactive aldehyde sites.

Normal human peripheral blood mononuclear cells (PBMC) were separated over Ficoll-Hypaque in a standard way, washed in Dulbecco's phosphate buffered saline containing $2 \%$ fetal calf serum, and centrifuged at $300 \mathrm{~g}$ for 10 minutes, then resuspended in medium RPMI 1640 plus $10 \%$ v/v fetal calf serum to give a concentration of $5 \times 10^{7} \mathrm{cells} / \mathrm{ml}$. The rest of the procedure was performed in a room thermostatically controlled at $4^{\circ} \mathrm{C}$. Slides were placed at random across the table of a Luckham orbital shaker adjusted to a rotational speed of 35 cycles per minute. The PMBC were filtered through a $15 \mu \mathrm{m}$ nylon gauze to remove clumps and each well (demarcated by the wax line) was loaded with $150 \mu \mathrm{l}$ of the filtered cells. The sections were then left for 30 minutes, removed from the table, rinsed in PBS, and fixed in $2 \%$ PBS buffered glutaraldehyde. Slides were stained with methyl green pyronin.

The third part of the tissue was cut into $1 \mathrm{~mm}$ cubes and incubated at $37^{\circ} \mathrm{C}$ for 30 minutes in a medium of PBS supplemented with $5 \mathrm{mM}$ glucose and $1.25 \mathrm{mM}$ sodium sulphate labelled with ${ }^{35} \mathrm{~S}$ (SJS 2P-Amersham International) with a specific activity of $74 \mathrm{MBq} / \mathrm{ml}$, then the tissue was removed and fixed in $2 \%$ glutaraldehyde in cacodylate buffer $\mathrm{pH} \mathrm{7.4}$ for four hours. The tissue was transferred to $70 \%$ alcohol saturated with glycine (to neutralise hemialdehydes which might cause chemical reduction of the silver salts in the autoradiographic emulsion) and finally, dehydrated and embedded in paraffin wax. Sections $(5 \mu \mathrm{m})$ were placed on gelatin coated slides, deparaffinised, and dried in an oven at $37^{\circ} \mathrm{C}$. In a dark room under an orange safety light the slides were dipped in a solution made from Ilford G5 emulsion in an equal volume of distilled water at $50^{\circ} \mathrm{C}$. Once dry the slides were left to develop in an airtight box for 30 days. At the end of this time the sections were fixed and stained with methyl green pyronin.

Ten sections of each specimen were examined, and only vessels cut in transverse section were assessed. The in vitro adhesion assay was performed by counting the number of adherent cells overlying three different structures: HEV or HEV-like vessels, other vessels, and nodal or synovial parenchyma. Sulphate incorporation was assessed by comparing the density of silver grains over HEV or HEV-like vessels, other vessels, and parenchyma. All statistics were calculated using a Wilcoxon two sample test.

\section{Results}

Four of the seven synovia from patients with rheumatoid arthritis (RA), one of the two with ankylosing spondylitis (AS), that from the patient with ulcerative colitis, and one of those with osteoarthritis (OA) contained areas of lymphocyte aggregation on at least one of the sections examined for lymphocyte adhesion and for sulphate uptake. One of the patients with RA, the remaining patient with AS, and seven of the OA group had no areas of lymphocyte aggregation on any of the preparations used in the study (Table 1).

Lymphocyte adhesion and sulphate uptake were seen in lymph node HEV and some, but not all, vessels within areas of lymphocyte accumulation in all the diseased synovia (Fig. 1). No lymphocyte adhesion or sulphate uptake was seen in vessels other than HEV in lymph nodes or in vessels outside areas of lymphocyte accumulation in diseased synovium (Tables 2 and 3 ).

The vessels in the synovium to which lymphocytes adhered and those that took up sulphate had the

Table 1 Number of cases of each arthropathy showing lymphocyte adhesion (LA) to or sulphate uptake (SU) by, or both, synovial endothelial cells

\begin{tabular}{lcccc}
\hline Arthropathy & Total cases & $\begin{array}{l}\text { Both LA } \\
\text { and SU }\end{array}$ & $\begin{array}{l}\text { LA but } \\
\text { not SU }\end{array}$ & $\begin{array}{l}\text { SU but } \\
\text { not LA }\end{array}$ \\
\hline Rheumatoid disease & & 7 & 4 & 1 \\
Osteoarthritis & 10 & 1 & 2 & 1 \\
Ankylosing spondylitis & 2 & 1 & 0 & 0 \\
Ulcerative colitis & 1 & 1 & 0 & 0 \\
\hline
\end{tabular}



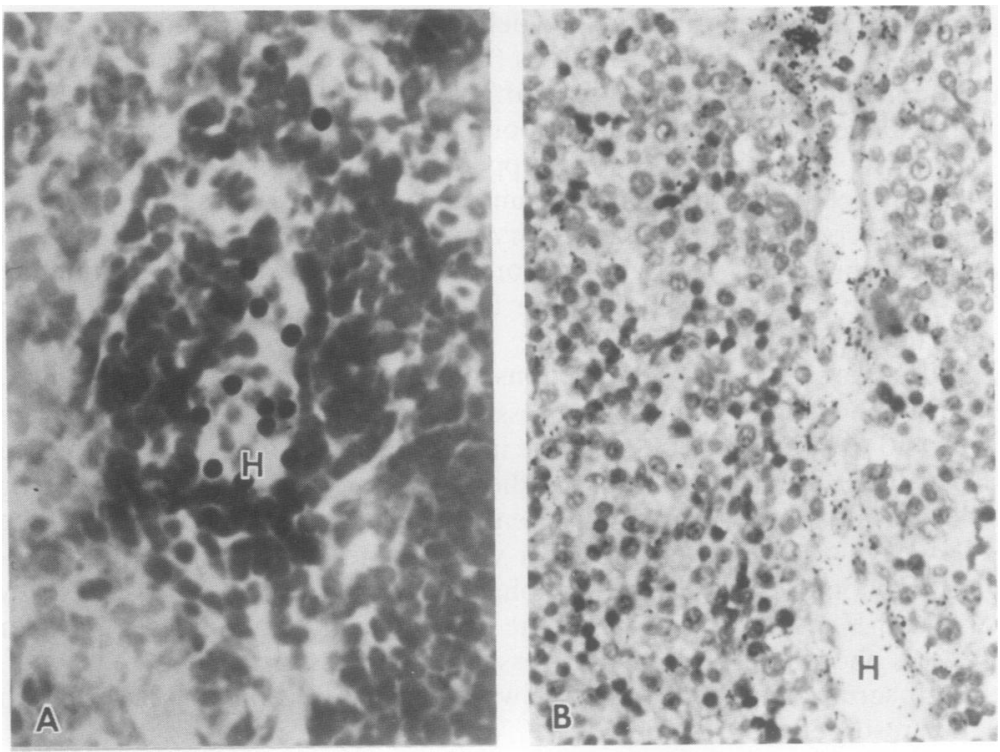

Fig. 1 HEV-type vessels in rheumatoid synovium.

(A) Adherent lymphocytes (darker than background lymphocytes in the section) overlie an HEV-like vessel $(H)$. (B) Emissions from radiosulphate are greater over the endothelial cells of $H E V$-like vessels $(H)$ than parenchyma.

morphology of venules. They were mostly lined by plump endothelial cells with pale open nuclei and pyroninophilic cytoplasm and were surrounded by a thick perivascular sheath, i.e., they had the morphological characteristics of lymph node HEV. Some, however, were lined by much flatter endothelial cells and were less obviously morphologically HEVlike. These vessels tended to have less adherent lymphocytes per endothelial cell and had a lower grain count per unit area of endothelium. Vessels $\mathbb{\Phi}$ were compared by a semiquantitative scoring syster $\overrightarrow{0}$ for average endothelial cell area in any one vessel, which + is conventional flat endothelium and +++ plump HEV-like endothelium. This system was use to derive data relating cross sectional endothelial cell area with lymphocyte adhesion and endothelial sulphate uptake (Table 4).

No HEV in the lymph nodes scored less than

Table 2 Comparison of average numbers of adherent lymphocytes over a standard area of HEV or HEV-like vessel, other vessels, and parenchyma*

\begin{tabular}{|c|c|c|c|c|c|c|}
\hline & \multicolumn{3}{|c|}{ Lymph node } & \multicolumn{3}{|c|}{ Synovium } \\
\hline & Number & Mean $(\%)$ & Range (\%) & Number & Mean $(\%)$ & Range $(\%)$ \\
\hline $\mathrm{HEV}$ & 417 & 100 & $15-273$ & 0 & - & - \\
\hline HEV-like vessels & 0 & - & - & 176 & 26 & $1 \cdot 2-83 \cdot 7$ \\
\hline Other vessels & 39 & 0.6 & $0-3 \cdot 2$ & 507 & 1.8 & $0-7$ \\
\hline Parenchyma & 500 & $1 \cdot 1$ & $0-2 \cdot 6$ & 1000 & $3 \cdot 3$ & $0-5 \cdot 2$ \\
\hline
\end{tabular}

${ }^{*}$ Results are expressed as a percentage of lymph node HEV.

Table 3 Comparison of average autoradiographic grain counts per standard area of HEV or HEV-like vessel, other vessels, and parenchyma*

\begin{tabular}{|c|c|c|c|c|c|c|}
\hline & \multicolumn{3}{|c|}{ Lymph node } & \multicolumn{3}{|c|}{ Synovium } \\
\hline & Number & Mean (\%) & Range $(\%)$ & Number & Mean (\%) & Range $(\%)$ \\
\hline HEV & 326 & 100 & $63-184$ & 0 & - & - \\
\hline HEV-like vessel & 0 & - & - & 223 & 21 & $2 \cdot 9-76 \cdot 1$ \\
\hline Other vessels & 51 & $1 \cdot 2$ & $0-4 \cdot 8$ & 496 & $2 \cdot 3$ & $0-7 \cdot 6$ \\
\hline Parenchyma & 500 & 0.9 & $0-5 \cdot 2$ & 1000 & 1.4 & $0-2 \cdot 7$ \\
\hline
\end{tabular}

${ }^{*}$ Results are expressed as a percentage of lymph node HEV. 
Table 4 Comparison of mean lymphocyte adhesion and autoradiographic grain counts in vessels of varying average endothelial plumpness*

\begin{tabular}{|c|c|c|c|c|}
\hline \multirow[t]{2}{*}{$\begin{array}{l}\text { Vessel } \\
\text { plumpness }\end{array}$} & \multicolumn{2}{|l|}{$\begin{array}{l}\text { Adherent } \\
\text { lymphocytes }\end{array}$} & \multicolumn{2}{|l|}{$\begin{array}{l}\text { Grain } \\
\text { counts }\end{array}$} \\
\hline & $\begin{array}{l}\text { Lymph } \\
\text { node (\%) }\end{array}$ & $\begin{array}{l}\text { Synovium } \\
(\%)\end{array}$ & $\begin{array}{l}\text { Lymph } \\
\text { node (\%) }\end{array}$ & $\begin{array}{l}\text { Synovium } \\
(\%)\end{array}$ \\
\hline $\begin{array}{r}+ \\
++ \\
+++\end{array}$ & $\begin{array}{cr}0 \cdot 6 & (39) \\
-\quad(0) \\
100 & (417)\end{array}$ & $\begin{array}{r}1 \cdot 8(507) \\
13 \cdot 3(166) \\
57 \cdot 2(251)\end{array}$ & $\begin{array}{cc}1 \cdot 2 & (51) \\
-100 & (326)\end{array}$ & $\begin{array}{r}2 \cdot 3(496) \\
11 \cdot 3(135) \\
49 \cdot 4(361)\end{array}$ \\
\hline
\end{tabular}

${ }^{*}$ Results are expressed as percentage of lymph node HEV of score +++ . The figures in parentheses show the number of observations.

+++ , whereas lymphocyte adhesion and sulphate uptake in synovium occurred in vessels designated ++ and +++ . In lymph nodes and synovium there was a significant difference in both lymphocyte adhesion and sulphate uptake between vessels of score + and $+++(\mathrm{p}<0.001)$ and in synovium between vessels of + and $++(p=0 \cdot 02)$ and ++ and $+++(p=0.01)$. The variation in overall lymphocyte adhesion and sulphate uptake between vessels in lymph nodes and synovium can therefore be explained, at least in part, by the heterogeneity of HEV-like vessels in synovium. There was, however, a significant difference also between lymph node HEV and synovial HEV-like vessels of score +++ for both lymphocyte adhesion and sulphate uptake $(\mathrm{p}<0.01)$, perhaps indicating that factors other than endothelial area may be influencing these manifestations of 'HEC-ness'.

\section{Discussion}

Little is known of the mechanisms controlling lymphocyte entry into diseased tissue. Although it has been previously suggested, on the basis of structural and histochemical similarities between lymph node $\mathrm{HEV}$ and some vessels in diseased synovium, that the local microvasculature might modulate lymphocyte migration into the tissue,,$^{3}$ this is the first time that endothelial cells in any one synovium have been shown to exhibit both of the assayable characteristics implicated in the control of lymphocyte traffic by HEC. Thus synovial HEV-like vessels would appear to be not only structurally and histochemically similar to lymph node HEV but also to share features indicative of the specific function of HEV. There is therefore strong evidence for suggesting that the two vessels are of the same functional type and that HEV-like vessels may influence lymphocyte entry into inflamed synovium. Lymph node HEV and synovial HEV-like vessels are not, however, identical, as witnessed by the numerical data presented here. This disparity could be due either to continuous recruitment within the synovium of HEV-like vessels, a proportion of which show suboptimal function during development, or the innate heterogeneity of this type of vessel. ${ }^{1011}$ This is the first report of endothelial sulphate uptake, of a type characteristic of HEV, outside lymphoid organs. Although there have been two recent reports of in vitro lymphocyte adhesion to vessels in rheumatoid synovium, ${ }^{11}{ }^{12}$ the present study differs from those in emphasising the lack of disease specificity of HEV-like changes in the synovial microvasculature. The only common factor in their development would seem to be lymphocyte aggregation in the synovium.

In addition to improving understanding of the basic mechanisms involved in lymphocyte entry into synovium these data may also have clinical relevance.

Monoclonal antibodies have been developed against the lymphocyte recognition site of $\mathrm{HEC}^{6} 10$ which prevent in vitro binding of lymphocytes. Early evidence from studies using these antibodies suggests that receptor mediated lymphocyte homing is organ specific. ${ }^{11}$ In their study of lymphocyte adhesion to rheumatoid synovial vessels Jalkanen $e t$ al produced some evidence to suggest that this specificity may extend to synovium. ${ }^{11}$ This observation could be exploited therapeutically. It is conceivable that by using these or similar antibodies to inhibit selective lymphocyte adhesion to synovial blood vessels or by interfering with synthesis of the sulphated macromolecule implicated in endothelial control of lymphocyte traffic it may be possible to reduce lymphocyte accumulation within diseased synovium. This could offer a novel approach to limiting tissue damage in all synovitides in which synovial injury is mediated through lymphocytes.

This work was funded by the Arthritis and Rheumatism Council. The microscope used was donated by the John Charnley Trust.

\section{References}

1 Dumonde D C. The rheumatological significance of lymphokines. In: Dumonde D C, Jasani M K, eds. Recognition of anti-rheumatic drugs. Lancaster: MTP Press, 1978: 167-92.

2 Denman A M. Immunological mechanisms and the rheumatic disease. In: Scott J T, ed. Copeman's textbook of the rheumatic diseases. Edinburgh: Churchill Livingstone, 1986: 331-54.

3 Freemont A J, Jones C J P. Bromley M. Andrews P. Changes in vascular endothelium related to lymphocyte collection in diseased synovia. Arthritis Rheum 1983; 26: 1427-33.

4 Freemont A J, Jones C J P. Light microscopic, histochemical and ultrastructural studies of human lymph node paracortical venules. J Anat 1983; 136: 349-62.

5 Woodruff J J, Kurtner B J. Adherence of lymphocytes to the 
high endothelium of lymph nodes in vitro. In: Blood cells and vessel walls. Amsterdam: Excerpta Medica. 1980): 243-56. (Ciba Foundation Symposium. No. 71).

6 Gallatin W M. Weissman I L. Butcher E C. A cell-surface molecule involved in organ-specific homing of lymphocytes. Nature 1983: 304: 30-4.

7 Andrews P. Ford W L. Stoddart R W. Metabolic studies of high-walled endothelium of post-capillary venules in rat lymph nodes. Blood cells and vessel walls. Amsterdam: Excerpta Medica, 1980: 211-30. (Ciba Foundation Symposium. No. 71.)

8 Andrews P. Milson D W. Stoddart R W. Glycoconjugates from high endothelial cells. I. Partial characterisation of a sulphated glycoconjugate from the HE cells of rat lymph nodes. J Cell Sci 1983; 59: 231-44.
9 Laitt R. Freemont A J. Stoddart R W. Matthews S. Sulphate uptake and lymphocyte migration in rat lymph nodes. $J$ Pathol 1986: 148: 121a.

10) Rasmussen R A. Chin Y H. Woodruff J J. Easton T G. Lymphocyte recognition of lymph node high endothelium. VII Cell surface proteins involved in adhesion defined by monoclonal anti-HEBFLN (A.11) antibody. J lmmunol 1985: 135: $19-24$.

11 Jalkanen S, Steere A C. Fox R I. Butcher E C. A distinct $\vec{\nabla}$ endothelial cell recognition system that controls lymphocutc 2 traffic into inflamed synovium. Science 1986: 233: 556-8.

12 Oppenheimer-Marks N. Ziff $M$. Binding of normal human mononuclear cells to blood vessels in rheumatoid arthritis. synovial membrane. Arthritis Rheum 1986: 29: 789-9?. 